\title{
Origem do plexo lombossacral de mocó (Kerondo rupestris)
}

Procássia Maria de Oliveira LACERDA $^{1}$

Carlos Eduardo Bezerra de MOURA $^{2}$

Maria Angélica MIGLINO ${ }^{1}$ Moacir Franco de OLIVEIRA ${ }^{3}$ José Fernando Gomes de ALBUQUERQUE ${ }^{3}$

Correspondência para: PROCÁSSIA MARIA DE OLIVEIRA LACERDA

Departamento de Cirurgia

Faculdade de Medicina Veterinária e Zootecnia

Universidade de São Paulo Av. Prof. Dr. Orlando Marques de Paiva, 87 05508-270 - São Paulo-SP procassia@usp.br

Recebido para publicação: 07/10/2004 Aprovado para publicação: 13/07/2005

\author{
1 - Departamento de Cirurgia da Faculdade de Medicina Veterinária e \\ Zootecnia da Universidade de São Paulo, São Paulo-SP \\ 2 - Departamento de Zootecnia da Universidade Federal do Rio Grande do \\ Norte, Natal-RN \\ 3 - Departamento de Ciência Animal da Escola Superior de Agricultura de \\ Mossoró, Mossoró-RN
}

\section{Resumo}

O mocó (Keredon rupestris), é um roedor da fauna silvestre brasileira, pertencente à família dos cavídeos, e da subfamília caviinae. No Brasil, o mocó já vem sendo criado em cativeiro com o objetivo de fornecer alimento, manter a espécie e proporcionar o desenvolvimento de pesquisas voltadas ao conhecimento mais aprofundado desta espécie. Nossa pesquisa visa conhecer a origem e os nervos resultantes do plexo lombossacral deste animal, fornecendo subsídios indispensáveis para o estudo da anatomia comparativa, especialmente dos mamíferos Silvestres. Foram utilizados 10 animais adultos de diferentes idades provenientes do Centro de Multiplicação de Animais Silvestres da ESAM (CEMAS-ESAM). Foram fixados em solução aquosa de formal a 10\% durante 48 horas, realizou-se dissecação de cada antímero a fim de expor os nervos através da retirada dos músculos psoas maior e psoas menor, cujos resultados foram registrados através de desenhos esquemáticos e imagens fotografadas. Observaram-se variações no número de vértebras lombares e sacrais destes animais, alterando a relação entre os nervos que dão origem ao plexo lombossacral que apresentou três tipos diferentes de constituição. As raízes ventrais originando-se a partir dos três últimos nervos lombares e dos três primeiros nervos sacrais correspondeu a $80 \%$ dos exemplares estudados, onde o tipo II $\left(\mathrm{L}_{5}, \mathrm{~L}_{6} \mathrm{~L}_{7}, \mathrm{~S}_{1} \mathrm{~S}_{2}\right.$ e $\left.\mathrm{S}_{3}\right)$. foi o mais comumente encontrado $(50 \%)$ das amostras. Os nervos considerados originários do plexo foram o Femoral, obturatório, isquiático, glúteo cranial, glúteo caudal e pudendo.

\section{Introdução}

Nos últimos anos, tem-se notado um aumento considerável na criação de animais silvestres com potencialidade para serem explorados na produção de alimentos, principalmente nas regiões tropicais e subtropicais do nosso planeta. Estes animais silvestres constituem uma fonte de proteína animal natural e renovável ${ }^{1}$.

Os roedores da fauna nordestina, em especial o mocó (Kerodon rupestris), apresentam inúmeras características biológicas desejáveis à domesticação, tais como a reprodução em cativeiro, hábito gregário, poligamia, prolificidade, sociedade e docilidade, além de possuir uma carne saborosa, muito apreciada pelos sertanejos. A longevidade do mocó em cativeiro mostra que por 11 anos, o animal consegue sobreviver comportando-se socialmente e formando grupos familiares ${ }^{2,3}$.

Este roedor, pertencente à família dos cavídeos, e da subfamilia caviinae, possui habitat mais especializado em relação às outras formas de caviinaes, e ao gênero Kerodon, que se assemelha muito aos gêneros Cavia e Galea. É um animal rupícula, 
não fossório, de focinho longo e estreito, com longas pernas propulsoras e de unhas rombas sobre coxins espessos que lhe permitem subir com facilidade em árvores e pedras. São excelentes saltadores escalando rochas e galhos de árvores, onde se alimentam de suas folhas ${ }^{4}$. Possuem hábito diurno e vivem geralmente em pequenas colônias feitas em buracos na terra, ou usam cavidades nas bordas das rochas ${ }^{5}$. De acordo com Lancher $\mathrm{Jr}^{4}{ }^{4}$ os mocós podem ser encontrados nos estados do nordeste e norte de Minas Gerais, porém habitam preferencialmente a catinga do semi-árido nordestino.

No Brasil, o mocó já vem sendo criado em cativeiro, com o objetivo de fornecer alimento, manter a espécie e proporcionar o desenvolvimento de pesquisas voltados ao conhecimento mais aprofundado desta espécie.

Especificamente no que diz respeito ao sistema neural do mocó, é de particular interesse para a anatomia comparativa o estudo da composição do plexo lombossacral, representativo da origem dos nervos que se destinam aos membros pélvicos. Segundo Barros, et al ${ }^{6}$ esse segmento anatômico é de considerável importância, uma vez que se relaciona aos aspectos evolutivos de postura e locomoção.

O plexo lombossacral é abordado por Tratados de Anatomia como sendo constituído pelos ramos ventrais dos últimos nervos lombares e primeiros sacrais, tendo este plexo origem nos segmentos da medula espinhal que se distribuem para os membros pélvicos e para as vísceras da região $0^{7,8,9}$.

Em algumas espécies de mamíferos, os aspectos referentes às particularidades do plexo já são considerados de acordo com as disposições específicas dos nervos, como o estudo anatômico e eletrofisiológico do nervo genitofemoral em ratos ${ }^{10}$.

Em animais silvestres podemos encontrar a morfologia dos plexos lombar e sacral em uma espécie de gorila, chimpanzé, Orangotanto e Gibbon ${ }^{11}$; o comportamento do plexo lombar em macacos Cebus apella ${ }^{6}$.
Mas precisamente em roedores silvestres Nunes ${ }^{12}$ descreveu o constituição deste plexo em cutias douradas (Dasprocta aguti) e Cooper e Schiller ${ }^{13}$ estudaram a anatomia do plexo lombossacral do porquinho da índia. Existem poucas informações na literatura sobre a morfologia do sistema nervoso do mocó (kerondon rupestris). No que se refere ao sistema nervoso periférico, podemos encontrar o estudo desenvolvido por Santana et $\mathrm{al}^{14}$ que caracterizam o plexo braquial desta espécie. A ausência de informações mais precisas revela a necessidade de se aprofundar as pesquisas deste animal, principalmente no que se refere ao sistema nervoso, por isso a nossa contribuição científica visa aumentar o acervo de dados sobre a anatomia específica desta espécie.

Nesta perspectiva, constitui-se objetivo central deste estudo identificar a origem e os nervos resultantes do plexo lombossacral do mocó (Keredon rupestris), estabelecendo um melhor entendimento da inervação da pelve e membro pélvico deste animal.

\section{Materiais e Métodos}

Para a realização desta pesquisa utilizamos dez mocós (Kerodon rupestris), sendo cinco machos e cinco fêmeas, adultos de diferentes idades, que vieram a óbito por causas naturais no Centro de Multiplicação de Animais Silvestres da Escola Superior de Agricultura de Mossoró (CEMAS/ESAM). Este é um criatório científico autorizado pelo IBAMA (Instituto Brasileiro do Meio Ambiente e Recursos Naturais Renováveis) que objetiva o fomento da pesquisa envolvendo animais que habitam a região semi-árida do nordeste brasileiro, cujo número de registro junto ao IBAMA-RN é 12.492-004.

As peças foram fixadas e conservadas em solução aquosa de formol a $10 \%$ por um período mínimo de 48 horas. Decorrido esse tempo, realizamos dissecação cuidadosa da origem do plexo lombossacral junto aos forames intervertebrais em ambos os 
antímeros. Buscamos expor o máximo possível cada vértebra espinhal lombar e sacral, afim de melhor visualizar os ramos ventrais da medula espinhal que originam o plexo lombossacral. Seguiu a dissecação cuidadosa da origem do plexo rebatendo os músculos psoas maior e psoas menor com ajuda de pinças oftálmicas e lâmina de bisturi 15. Esse procedimento foi realizado a olho nu ou, quando necessário, utilizou-se lupa de aumento 10X para melhor visualização dos nervos. Após a dissecação utilizamos água oxigenada volume 20 embebido em algodão durante 12 horas promovendo um clareamento dos nervos para facilitar a identificação. Após a dissecação analisamos os 20 plexos originados desse procedimento, tendo em vista os antímeros direito e esquerdo.

A documentação dos resultados foi realizada a partir de desenhos esquemáticos e fotografias da origem dos nervos que compõe o plexo lombossacral.

Para descrever os resultados encontrados utilizamos a nomenclatura universal do International Committee on Veterinary Gross Anatomical Nomenclature ${ }^{15}$

Considerando a grande variabilidade apresentada pelo plexo lombossacral do mocó (Kerodon rupestris) nos aspectos estudados, e por ser uma amostra relativamente pequena, optou-se por uma análise estatística simplificada, a qual se resume em analisar os dados de forma descritiva e termos de percentagem e variabilidade (desvio padrão simples).

\section{Resultados}

Das dez espécimes dissecadas verificamos uma variação no número de vértebras lombares e sacrais, sendo considerada a primeira vértebra lombar caudalmente a última costela. Em 7 animais $(70 \pm 14,49 \%)$ há presença de sete vértebras lombares, nas outras 3 espécimes (30 $\pm 14,49 \%$ ) identificamos apenas seis destas vértebras. As vértebras sacrais variarão entre $\mathrm{S}_{3}$ e $\mathrm{S}_{4}$, onde a presença de $\mathrm{S}_{4}$ foi verificada em apenas 2 dos animais dissecados $(20 \pm$ $12,65 \%$ ), e seus ramos não participaram da formação do plexo. Considerando o segmento vertebral lombar e sacral em conjunto, constatamos que estes formam quatro tipos diferentes de disposição $\mathrm{L}_{7} \mathrm{e}$ $\mathrm{S}_{3} ; \mathrm{L}_{7}$ e $\mathrm{S}_{4} ; \mathrm{L}_{6}$ e $\mathrm{S}_{3} ;$ e $\mathrm{L}_{6}$ e $\mathrm{S}_{4}$; sendo o tipo $\mathrm{L}_{7}$ e $\mathrm{S}_{3}$ o mais comumente encontrado $(60 \%)$, revelando o padrão anatômico para a espécie.

A origem do plexo lombossacral foi classificado em Três tipos (Figuras 1, 2, 3) sendo o tipo II $\left(\mathrm{L}_{5}, \mathrm{~L}_{6}, \mathrm{~L}_{7}\right.$ e $\mathrm{S}_{1}, \mathrm{~S}_{2}$ e $\left.\mathrm{S}_{3}\right)$ o mais freqüente $(50 \%)$ (tabela 1$)$. Logo, podemos afirmar que o plexo lombossacral no mocó é resultante das comunicações estabelecidas principalmente, entre os ramos ventrais dos três últimos nervos lombares e dos três primeiros sacrais (Figura 2).

Consideramos participantes da formação do plexo lombossacral do Mocó o nervo femoral, obturatório, isquiático, glúteo cranial, glúteo caudal e pudendo. Outros nervos menores como aqueles destinados a músculos da região glútea e pelve, em geral, nascem como ramo de algum outro nervo e não do plexo. Cada nervo originário do plexo recebe contribuição de duas ou mais raízes ventrais dos nervos espinhais, sendo raras as exceções (tabela 2).

$\mathrm{Na}$ constituição do nervo femoral encontramos uma variação significativa nos ramos ventrais dos nervos lombares que se unem para formar este nervo, no entanto, em três antímeros apenas um ramo deu origem direta a este nervo, sem comunicações com outros.

O nervo obturatório surge a partir de contribuições dos últimos nervos lombares. No antímero esquerdo, em 4 animais $(40 \pm 15,81 \%)$ a formação do nervo está relacionada com a união dos 3 últimos nervos lombares e os outros $6(60 \pm 15,81 \%)$ originam-se através dos dois últimos lombares. No antímero direito em 4 casos $(40 \pm 15,81 \%)$ os dois últimos nervos lombares participam da sua origem e em 6 espécimes $(60 \pm 15,49 \%)$ esse nervo surge por meio de interações entre os 3 últimos nervos 
lombares.

A confluência dos ramos ventrais dos dois últimos nervos lombares com os dois primeiros sacrais na maioria dos casos originou o nervo isquiático, mas a sua formação a partir da união dois últimos nervos lombares com um ramo do primeiro nervo sacral foi verificado em três plexos.

O nervo glúteo cranial surge quase que exclusivamente do último nervo lombar, sendo encontrado em 9 plexos dissecados $(90 \pm 9,49 \%)$ no antímero direito e 8 plexos $(80 \pm 12,65 \%)$ no antímero esquerdo. A presença de S1 na constituição deste nervo foi verificada em 3 antímeros $(30 \pm 14,49 \%)$, sendo 1 caso no antímero direito e 2 casos no antímero esquerdo.

No antímero direito o nervo glúteo caudal originou-se do ramo ventral do último nervo lombar em 7 plexos $(70 \pm 14,49 \%$ ); nos outros 3 casos formou-se a partir da união de um ramo do último nervo lombar com o primeiro sacral. $O$ nervo glúteo caudal no antímero esquerdo recebeu contribuição do último nervo lombar e primeiro sacral em 5 amostras $(50 \pm 15,81 \%)$ e em 4 casos (40 \pm $15,49 \%$ ) surge apenas da última vértebra lombar. Em 1 espécime no antímero esquerdo, não foi encontrada a origem deste nervo.

O nervo pudendo recebe contribuições quase que exclusivamente, dos ramos que emergem de S2 e S3, sendo que no antímero esquerdo 2 plexos $(20 \pm 12,65 \%)$ originaram-se unicamente a partir de S3.

\section{Discussão}

A disposição do plexo lombossacral em mocós (Kerodon rupestris) apresenta características morfológicas parecidas com o que é citado pelos tratados de anatomia veterinária, mas a origem anatômica dos nervos deste plexo demonstrou uma certa variação devido à diferença no número de vértebras lombares envolvidas em cada amostra dessa espécie.

A variação no número de vértebras determinou a distribuição do plexo lombossacral do mocó em três tipos diferente, onde o plexo com origem em $\mathrm{L}_{5}, \mathrm{~L}_{6}, \mathrm{~L}_{7}, \mathrm{~S}_{1}, \mathrm{~S}_{2}$ e $\mathrm{S}_{3}$, caracterizando o tipo II, foi o mais comumente encontrado. Embora Greenawsay et al. ${ }^{16}$ também tenham encontrado diferenças nos números de vértebras quando estudaram este plexo em coelhos, eles não mencionam as diferenças nos locais de origem dos nervos. Em cutias apenas um tipo de plexo foi caracterizado $\left(\mathrm{L}_{6}, \mathrm{~L}_{7}\right.$ e $\left.\mathrm{S}_{1}\right)$, não mencionando a variação no número de vértebras destes animais ${ }^{12}$.

Consideramos constituintes do plexo lombossacral do mocó (Kerodon rupestris) os nervos femoral, obturatório, isquiático, glúteo cranial, glúteo caudal e pudendo do plexo lombossacral do mocó. Verificamos discordância entre os autores de tratados de anatomia quanto aos nervos que originam-se deste plexo. Getty faz separação entre plexo lombar e sacral, não considerando sua formação em conjunto. Habel e Robert ${ }^{17}$ consideraram como participantes do plexo lombossacral em animais domésticos os nervos femoral, obturatório, isquiático e peroneal. Frandson ${ }^{18}$ por outro lado descreve os nervos glúteo cranial, glúteo caudal, femoral, obturatorio, isquiático e peroneal, como integrantes deste plexo.

Em animais silvestres alguns autores fizeram uma abordagem dos nervos espinhais encontrados em cada plexo separadamente, mas citam a participação de um tronco lombossacral. Em cutias a

Tabela 1 - Tipos de plexos lombossacrais encontrados no Mocó

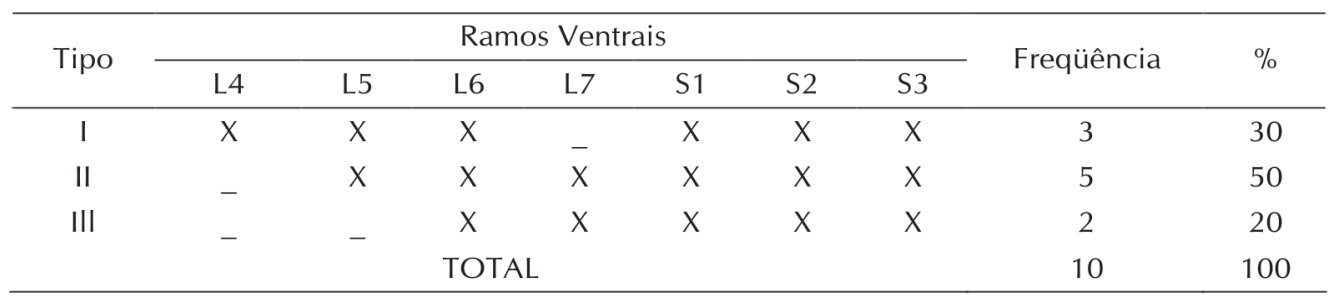


Tabela 2 - Origem e freqüência dos nervos que compreendem o plexo lombossacral do mocó (Kerondon rupestris) de acordo com o antímero Direito $(A D)$ e antímero Esquerdo (AE) respeitando a variação do número de vértebras lombares

\begin{tabular}{|c|c|c|c|c|c|c|}
\hline \multicolumn{7}{|c|}{ Animais com 6 vértebras lombares } \\
\hline Nervos & \multicolumn{2}{|c|}{ Origem } & \multicolumn{2}{|c|}{ Frequencia } & \multicolumn{2}{|c|}{$\%$} \\
\hline \multirow{3}{*}{ Femoral } & $\mathrm{AD}$ & $\mathrm{AE}$ & $\mathrm{AD}$ & $\mathrm{AE}$ & $\mathrm{AD}$ & $\mathrm{AE}$ \\
\hline & L4 e L5 & L4 e L5 & 2 & 2 & 67 & 67 \\
\hline & L4, L5 e L6 & L4, L5 e L6 & 1 & 1 & 33 & 33 \\
\hline \multirow{2}{*}{ Obturatório } & L5 e L6 & L5 e L6 & 1 & 2 & 33 & 33 \\
\hline & L4, L5 e L6 & L4, L5 e L6 & 2 & 1 & 67 & 67 \\
\hline Isquiático & L5, L6, S1 ,S2 & L5, L6, S1, S2 & 3 & 3 & 100 & 100 \\
\hline Gluteo Cranial & L6 & L6 & 3 & 3 & 100 & 100 \\
\hline \multirow{2}{*}{ Gluteo Caudal } & L6 & L6 & 3 & 2 & 100 & 67 \\
\hline & - & L6 e S1 & - & 1 & - & 33 \\
\hline Pudendo & S2 e S3 & S2 e S3 & 3 & 3 & 100 & 100 \\
\hline \multicolumn{7}{|c|}{ Animais com 7 vértebras lombares } \\
\hline \multirow{2}{*}{ Nervos } & \multicolumn{2}{|c|}{ Origem } & \multicolumn{2}{|c|}{ Frequencia } & \multicolumn{2}{|c|}{$\%$} \\
\hline & $\mathrm{AD}$ & $\mathrm{AE}$ & AD & $\mathrm{AE}$ & $\mathrm{AD}$ & $\mathrm{AE}$ \\
\hline \multirow{4}{*}{ Femoral } & L5, L6 e L7 & L5, L6 e L7 & 1 & 1 & 14 & 14 \\
\hline & L5 e L6 & L5 e L6 & 3 & 5 & 43 & 72 \\
\hline & L6 e L7 & L6 e L7 & 1 & 0 & 14 & 0 \\
\hline & L6 & L6 & 2 & 1 & 29 & 14 \\
\hline \multirow{2}{*}{ Obturatório } & L5, L6 e L7 & L5,L6 e L7 & 4 & 3 & 57 & 43 \\
\hline & L6 e L7 & L6 e L7 & 3 & 4 & 43 & 57 \\
\hline \multirow{2}{*}{ Isquiático } & L6, L7, S1, S2 & L6, L7, S1, S2 & 6 & 5 & 86 & 71 \\
\hline & L6, L7, S1 & L6, L7, S1 & 1 & 2 & 14 & 29 \\
\hline \multirow{2}{*}{ Gluteo Cranial } & L7 e S1 & L7 e S1 & 1 & 2 & 14 & 71 \\
\hline & L7 & L7 & 6 & 5 & 86 & 29 \\
\hline \multirow{3}{*}{ Gluteo Caudal } & L7 e S1 & L7 e S1 & 3 & 4 & 43 & 57 \\
\hline & L7 & L7 & 4 & 2 & 57 & 29 \\
\hline & - & Ausente & - & 1 & - & 14 \\
\hline \multirow{2}{*}{ Pudendo } & S2 e S3 & S2 e S3 & 7 & 5 & 100 & 71 \\
\hline & - & $\mathrm{S} 3$ & - & 2 & - & 29 \\
\hline
\end{tabular}

formação do plexo surge por meio de um tronco lombossacral que emite ramos a partir dos dois últimos nervos lombares e do primeiro sacral. A disposição dos plexos em gorila, chimpanzé, orangotango e gibbon, foram descritos separadamente, no entanto os autores fazem referência a um tronco lombossacral originando a partir dos dois últimos nervos lombares e dos dois primeiros sacrais, sendo que tal disposição varia de acordo com cada espécie estudada $\left(\right.$ Hepburn $^{11}$ citado por Barros $\left.{ }^{6}\right)$. Cooper e Schiller ${ }^{13}$ ao descreverem a anatomia do porquinho da índia, reservaram-se a mencionar os nervos dos plexos separadamente não fazendo referência à presença de um tronco lombossacral. Barros ${ }^{6}$ ao estudar os macacos Cebbus apella, descreveram o plexo lombar separado do sacral, uma vez que não constataram, em 

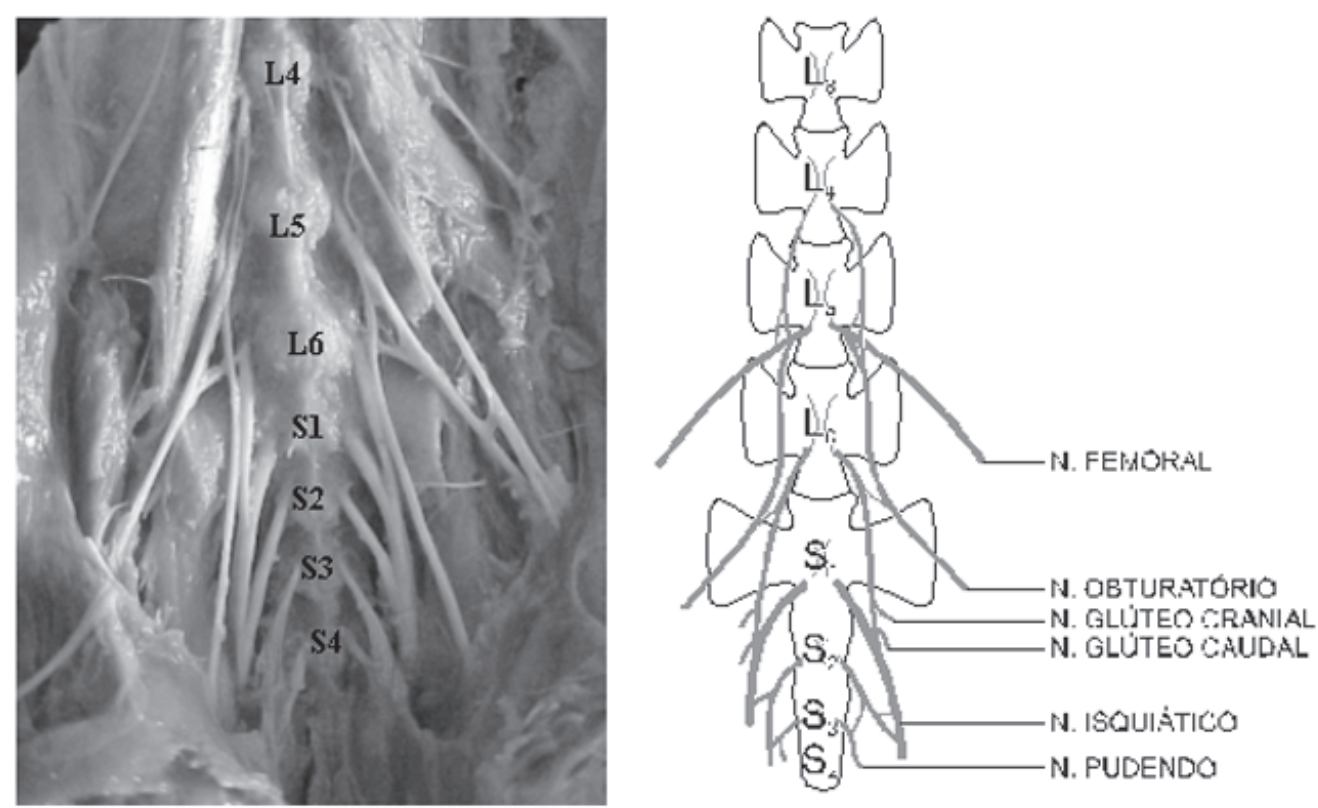

Figura 1 - Plexo lombossacral do tipo I (L4, L5, L6, S1, S2 eS3) observado em mocós. Descrição esquemática dos ramos ventrais dos nervos espinhais que participam da formação deste plexo
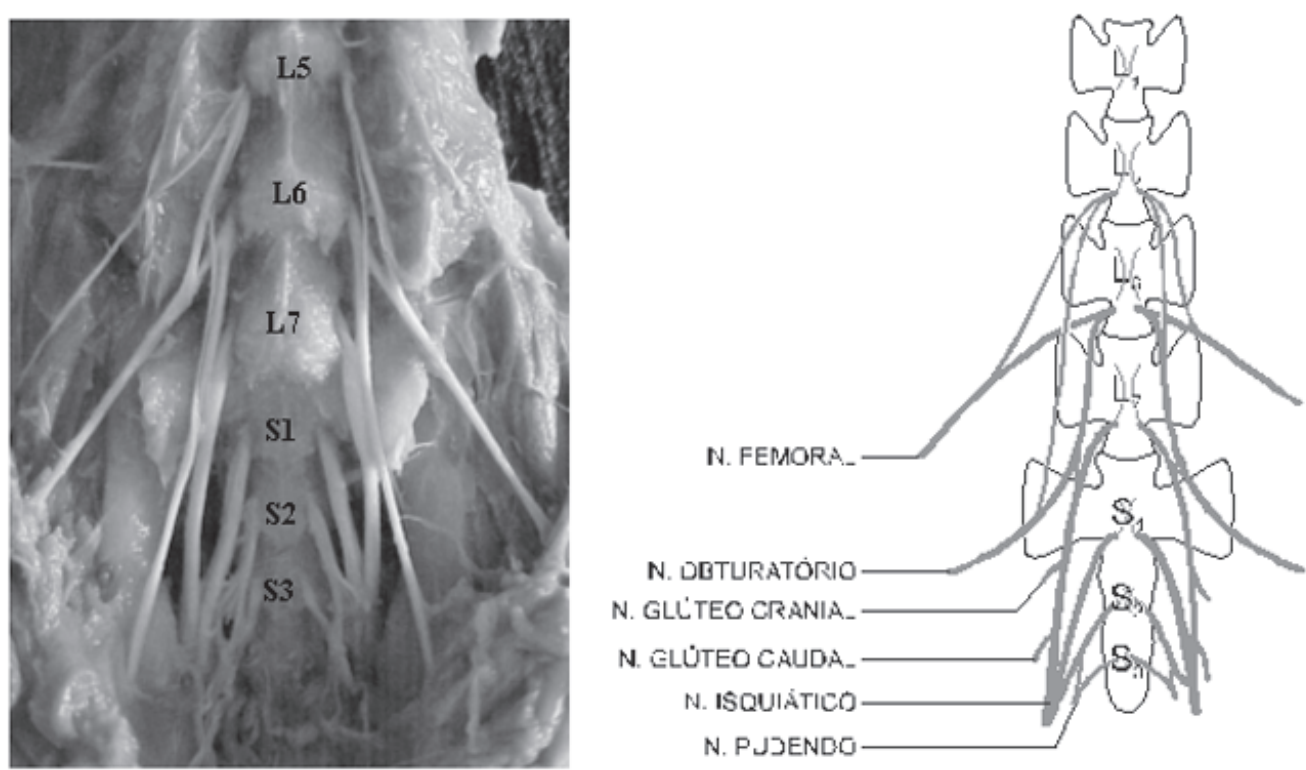

Figura 2 - Plexo lombossacral do tipo II (L5, L6, L7, S1, S2 eS3.), formação mais freqüente encontrado em mocós. Observar a disposição dos ramos ventrais dos nervos espinhais que participam da formação do plexo

nenhum caso, a participação de nervos sacrais na constituição do plexo lombar.

$\mathrm{O}$ ramo ventral $\mathrm{L}_{4}$ constitui o último nervo lombar de nossas preparações. É importante salientar que estes resultados somam-se aos de Frandson ${ }^{18}$ em animais domésticos, aos de Cooper e Schiller ${ }^{13}$, Hepburn $^{11}$ e Barros ${ }^{6}$ em animais silvestres. Este ramo participa do plexo lombossacral enviando um pequeno filete para $\mathrm{L}_{5}$, originando os nervos femoral e obturatório. É importante notar que esse nervo só está 

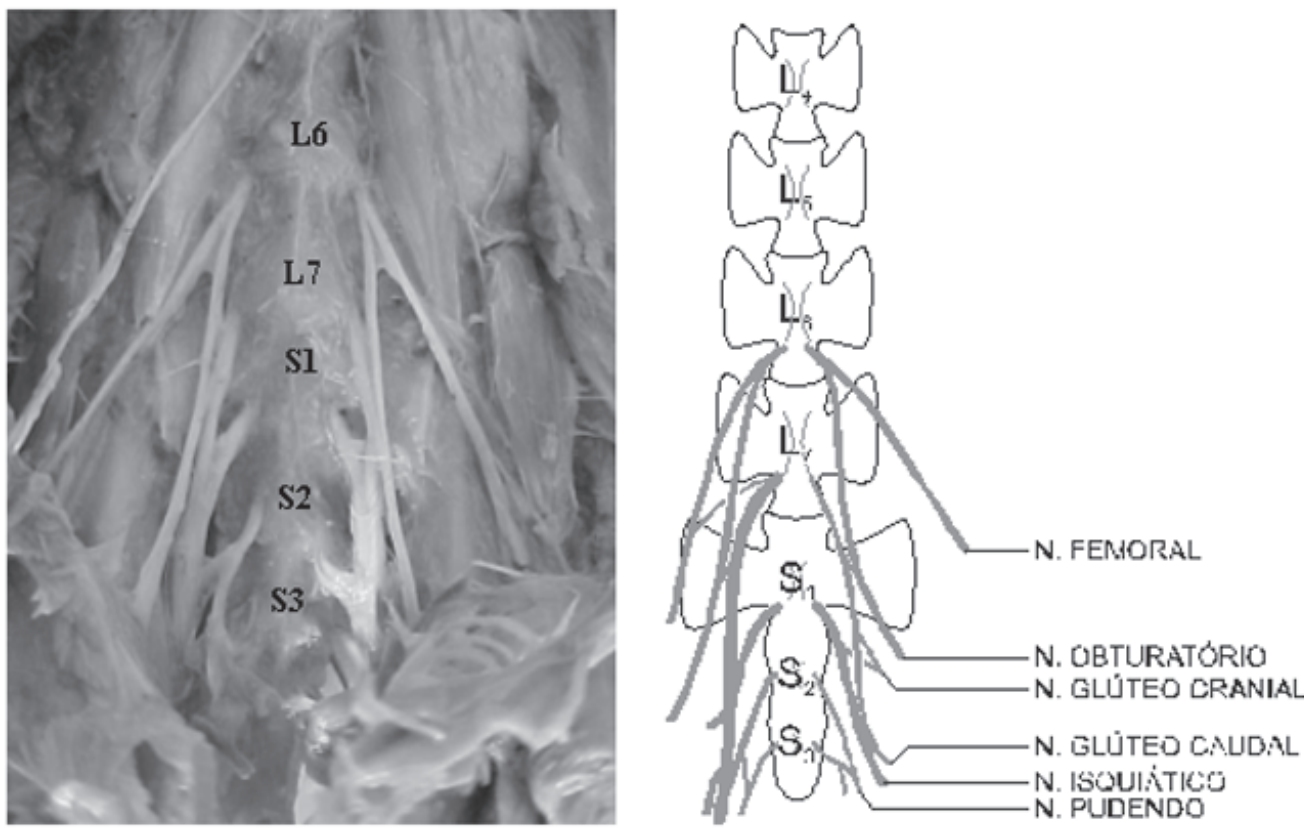

Figura 3 - Plexo lombossacral do tipo III (L5, L6, L7, S1, S2 eS3.) encontrados em mocós (tipo menos freqüente). Observar os ramos ventrais dos nervos espinhais que participam da formação deste plexo

presente em animais que apresentaram 6 vértebras lombares, nos espécimes constituídos de 7 vértebras lombares a origem deste filete ocorre a partir de $\mathrm{L}_{5}$. Nunes e Silvino ${ }^{12}$ citam que em cutias, há uma participação significativa dos ramos ventrais de $\mathrm{L}_{3}$ e $\mathrm{L}_{4}$, no entanto não encontramos $\mathrm{L}_{3}$ participando do referido plexo no mocó.

O envolvimento do ramo ventral do quinto nervo lombar $\left(\mathrm{L}_{5}\right)$ na formação do plexo é bastante variado, estando relacionado com a formação dos nervos femoral, obturatório e isquiático. Em cutias os ramos ventrais de $\mathrm{L}_{5}$ estão presentes em todos os $\operatorname{casos}{ }^{12}$.

Em primatas a participação de $\mathrm{S}_{1} \mathrm{e}$ $S_{2}$ na formação do plexo lombossacral é mais comum, fato também verificado no mocó a presença do terceiro componente sacral $\left(\mathrm{S}_{3}\right)$ com contribuição de $\mathrm{S}_{2}$ foi encontrada na formação do nervo pudendo, mas em dois casos (antímero esquerdo) este nervo originou-se exclusivamente de $\mathrm{S}_{3}$. Embora tenham referências onde à participação de $\mathrm{S}_{3}$ é efetiva na formação do plexo em primatas $^{6,19}$, roedores $^{16,20}$, animais silvestre ${ }^{10}$ e domésticos ${ }^{7,8,9,18}$, a maioria dos estudos mostra que a presença dos nervos sacrais na formação do plexo limita-se aos seus dois primeiros constituintes $\left(\mathrm{S}_{1}\right.$ e $\left.\mathrm{S}_{2}\right)$.

$\mathrm{Em}$ alguns exemplares encontramos quatro vértebras sacrais, sendo que os nervos que emergiam de seus forames intervertebrais não contribuíram na origem dos nervos do plexo lombossacral do mocó. Barros et. al. cita este ramo contribuindo na formação do nervo pudendo em 1 caso (5\%) no Cebbus apella.

\section{Conclusões}

O plexo lombossacral do mocó (Kerondon rupestres) apresentou variações anatômicas freqüentes na origem dos nervos que o compõe. Originou-se a partir de comunicações entre os ramos ventrais dos nervos espinhais que emergem das três ultimas vértebras lombares e três primeiras sacrais. Estes animais possuem um número variável de vértebras lombares $\left(\mathrm{L}_{6}\right.$ e $\left.\mathrm{L}_{7}\right)$ e sacrais $\left(\mathrm{S}_{3}\right.$ e $\left.\mathrm{S}_{4}\right)$, o que justificou a maior 
variação na origem dos nervos. Encontramos três tipos de plexos, sendo o tipo II o mais comumente encontrado, formado por $\mathrm{L}_{5}, \mathrm{~L}_{6} \mathrm{~L}_{7}, \mathrm{~S}_{1}, \mathrm{~S}_{2}$ e $\mathrm{S}_{3}$. Os nervos constituintes do plexo l,ombossacral do mocó são o femoral. obturatório, isquiático, glúteo cranial, glúteo caudal e pudendo.

\section{Origin of lumbar sacral plexus of rock cavy (Kerondo rupestris)}

\section{Abstract}

Rock cavy (Kerondon rupestris) is a rodent of the Brazilian wild fauna, belonging to the cavied family, and to the caviinae under family. In Brazil, this animal is already been raised in captivity with the aim of food supply, to preserve the species and to offer subsidy to the research development concerning to the deeper knowledge of these species. To know the origin and the nerves of the rock cavy (Keredon rupestris) lumbar sacral plexus, supplying indispensable subsidies for the study of the comparative anatomy, especially of the wild mammals, we intended to accomplish this research. Ten adult animals of different ages from the Wild Animals Multiplication Center (CEMAS) of the Superior School of Agriculture of Mossoró (ESAM) were used. The segments were fastened in 10\% aqueous solution of formal for 48 hours, followed by dissection in order to expose the nerves by the retreat of the muscles, psoas major and psoas minor, and the results were registered by schematic drawings and photographed images. Differences were observed in the number of lumbar and sacral vertebrae of these animals. The lumbar sacral Plexus presented their ventral roots starting from the last three lumbar nerves and from the first three sacral nerves, corresponding to $80 \%$ of the studied animals. The type II $\left(\mathrm{L}_{5}, \mathrm{~L}_{6} \mathrm{~L}_{7}, \mathrm{~S}_{1} \mathrm{~S}_{2}\right.$ e $\left.\mathrm{S}_{3}\right)$ was the most commonly found (50\%) of the between samples. Considered nerves, originated in the plexus, were: femoral, obturatory, ischiatic, cranial gluteus, caudal gluteus and pudendus.

\section{Referências}

1 VON RICHER, W. The utilization and management of will animals. Animal Research and Development, v. 10, p. 93-103, 1979.

2 ROBERTS, M.; MALINIAK, E.; DEAL, M. The reproductive biology of the rock cavy, Kerodon rupestris, in captivity. A study of reproductive adaptation in a trophic specialist. Mammalia, v. 48, n. 2, p. 253266, 1984.

3 PINHEIRO, M. J.; ANDRADE.,S. A.; CUNHA, J. N. Preservação e exploração de animais silvestres nativos: preá, cutia e mocó. Caatinga, v. 6, p. 28-49, 1989.

4 LANCHER JR., T. E. The comparative social behavior of kerodon rupestres and Galea spixii and the evolution of behaviour in the caviidae. Bulletin of Museum Natural History, n. 17, p. 1-71, 1981.

5 CRANDALL, L. S. Faily Caviidae. In: Manangement od the wild mammals captivity. Chicago: University od Chicago Press, 1964. p. 247-
Key-words:

Anatomy.

Lombossacral plexus.

Rock cavy

Wild animals.
250.

6 BARROS, R. A.; et al. Constituição do plexos lombar em macaco Cebus apella. Brazilian journal of Veterinary Research and Animal Science São Paulo, v.40, n.5. pg 373-381, 2003.

7 KRAHMER, R; SHCORODER, L. Anatomia de los animales domésticos. Zaragoza- Espanha: Acribia, 1979.

8 DYCE, K. M. ; SACK, W. O.; WENSING, C. J. G. Tratado de anatomia veterinária. 2 . ed. Rio de Janeiro: Guanabara Koogan, 1996.

9 GETTY, R. Sisson/ Grossman: anatomia dos animais domésticos. 5. ed. Rio de Janeiro: Guanabara Koogan, 1986. 2 v.

10 ZEMPOALTECA, R.; MARTINEZ-GOMES, M.; HUDSON, R.; CRUZ, Y.; LUCIO, R. A. An anatomical and electrophyisiological study of the genitofemoral nerve and some of its targets in the male rat. Journal of Anatomy. v. 201. p. 493-505. 2002.

11 HEPBURN, D. The comparative anatomy of the muscles and of the superior and inferior extremities of 
the anthropoid apes Part II. Journal Anatomy of

Physiology, p. 324-356, 1892

12 NUNES, L. C. ; SILVINO, M. J. Formação do plexo lombossacral em cutia dourada (Dasprocta aguti). In: CONGRESSO BRASILEIRO DE ANATOMIA, 17. 1996, Fortaleza, CE, p.139.

13 COOPER, G. , SCHILLER, A. I. Anatomy of the guinea pig. Cambridge: Harvard University Press, 1975, p. 253-287.

14 SANTANA, J. J.; et al. Origem do plexo braquial do mocó (kerondon rupestris, Wild 1820). Brazilian Journal of Veterinary Research and Animal Science. v. 40, n. 6 , p. 391-396, 2003.

15 INTERNATIONAL COMMITTEE ON VETERINARY GROSS ANATOMICAL NOMENCLATURE. Nomina anatomica veterinária. $4 \mathrm{ed}$. New York, 1994. (Togheter with nomina histological, 2 ed., 1992 and nomina embriologica veterinaria, 1992).

16 GREENAWAY; J. B.; et al. Anatomy of the lumbosacral spimal cord in rabbits. Journal of the American animal Hospital Association. Januaryfebruary, p. 27-34, 2001.

17 HABEL, A. DE LAHUNTA; ROBERTY. W.B. Appliedy veterinaria anatomy. Washington: Saunders Company, 1986.

18 FRANDSON, R. R. Anatomia e fisiologia dos animais domésticos. 2. ed. Rio de Janeiro: Guanabara Koogan, 1979.

19 EL-ASSY, Y. S. Beitrage zur morphologie des peripheren nervensystems der primaten. Gegenbaur Morph., p. 476, 1966

20 GREENE, E. C. The American Philosophical Society, Anatomy of the rat. Philadelphia. 1935. 